\title{
SPIN RESONANCE INVESTIGATIONS ON WATER-BASED MAGNETITE FERROFLUID
}

\author{
A. Sharkar ${ }^{12}$, M. Chand ${ }^{1}$, S. Kumar', V.N. Smah'. \\ G.A. Basked ${ }^{3}$ S. Thakur ${ }^{2}$, R.P. Pant ${ }^{\mathrm{I}}$

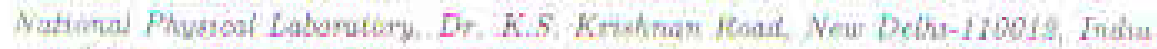

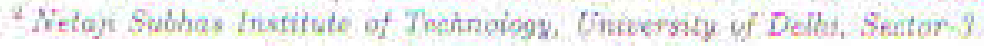 \\ Duarka, New Delhi fliajok india

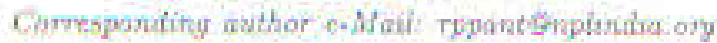

\begin{abstract}
Iit this work, wr have investigated a water-basted fertoffula for its inagnetic propertica. The namoparticjes of ferrofluid were szrehisized by a chemical coptecipitation nnite. Magnesite taanosiarticles wrre chemically prepared by coprecipatation of roverse micolles in

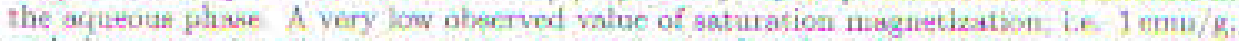
and the magnetic sulisolropy energy constant wro fotund in the samples. This was ex. plaineal by dead baxer thoory and effect of double surfaxtant roiting. Frrmanametic

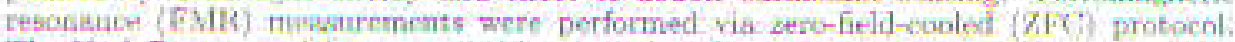
The Neel-Brown modet was applind by nesming the resconance Geld as the applibed fiedd

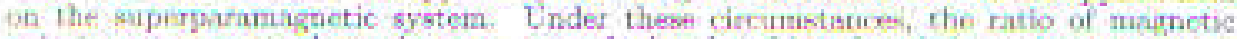
inisotropy oncras to thermel energy was exlculated and it is found that it bcoomes unitv $-225 \mathrm{~K}$ for the particles. which are antipuratlel to the applied field.
\end{abstract}

1. Tntroduction. The existence of hocking effects in munomaterials is characterized by a critical temperature, i.e. it blockiug temperature $\left(I_{\mathrm{h}}\right)$. In addition to ils temperature dependence, $T_{\mathrm{b}}$ ulso depends on ot her key factors like the volime af portjcles (V), magnetio anisotropy $(K)$ and the timestede of the meseuning instrument $\left(\gamma_{\mathrm{m}}\right)$, making it as one of the ill-definect parameters in nanomagnetism 1). Whet the thasscole wisdow is large than the superparamaguesie rolaxation time ( + ) then the syntem displays superpsramagnetisu. Ot the other hand, when $T \geq T_{m}$ the syatem is meisurod wo be in the blocked atate In this stittr, the quist-stutic properties of the system ace observed. Mauy techuiques have been employed to arcerzain $T_{b}$ in wach systoms and atnong them the most frequentily used ons are Supercouducting Quantum Interference Device (SQULID), Vibrating Srimning Magnetometer (VSM), ac-susceptilhility meissurements and Mossbauer epectroscopy [1.2]. But the ability of FerroMLgnetic Resounnce (FMR) for find. mig $T_{b}$ his been explored only in $\mathrm{s}$ few cases 33. 4 . The aim of this work is to study

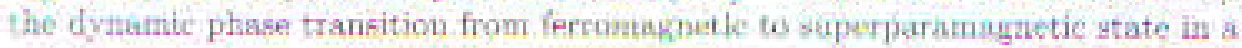
water based imgnetite ferrofluid by using the famons Neel-Brown model in FMn tesitits,

2. Synthesis and experimental methodk. $\mathrm{Fe}_{3} \mathrm{O}_{4}$ nanoporticles (FNPs) wert kynthesizod via a chemical route A detailed schematic diagram of the syothisis procodure is shown in Fig. 1. The structural chatacterization was performed using s powder X-riy difractometer and IIRTEML The magnetization messure meats wore made on these samples hy a Lakeahore make VSM model 7.400. The

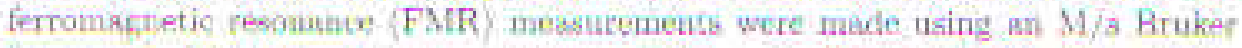
biospin model A3O0): Before measurements, the signal chumel wiss culibrated at rom temperature using the I $\mathrm{mg}$ DPPH standard 


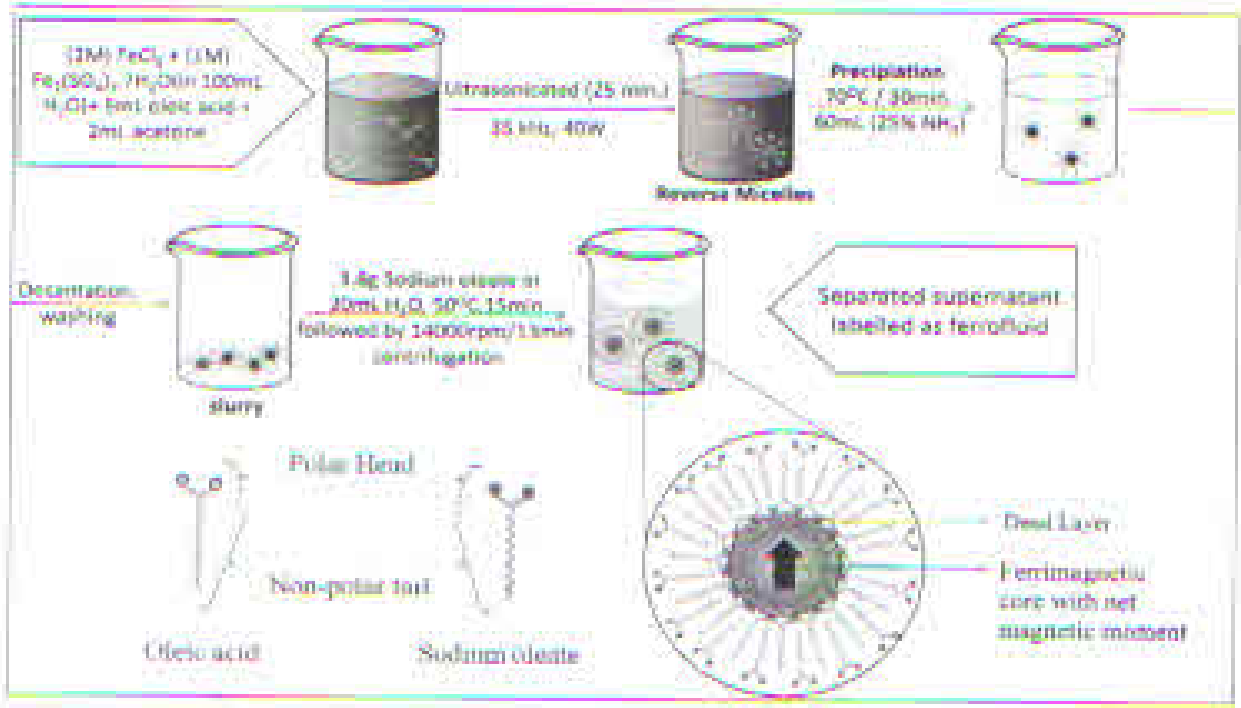

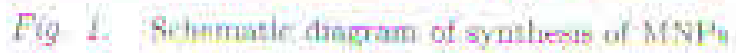

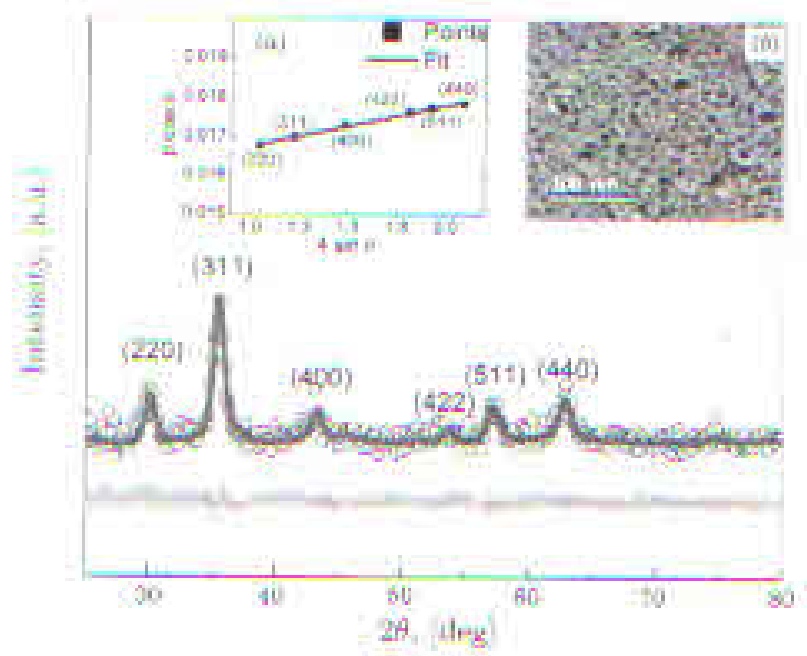

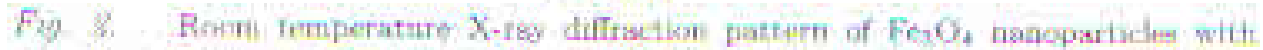

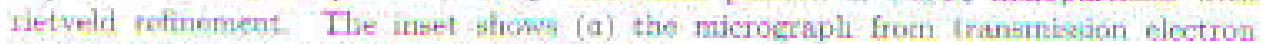
microsrope (TEM), (b) a Wijtiamson Hall plot

\section{Results and discussion.}

3.1. Struciural characterization: Fig. 2 shows the Powder X-ray Diffrim: then Patem (PXRD) pattern of Fo3 $\mathrm{O}_{2}$ ferrotuid drops dried on o gless stide in ambient-conditioss The refined peak pasitions $(20)$ asud the full width al, balf. maximum (FWHM) whases (ot) abuand from rictveid refinement were usox in the Williatnson-Hall equation $\beta \cos \theta=4 z \sin \theta-\lambda / D$ to calculate the average $r r y$ tallite sase $(D)$ and the strain $(E)$ indured in the $N P_{3}$, where $\lambda$ is the wavelength of $\mathrm{X}$-ray (Inset fol). The average erystallite size (D) and the nt rain $(\mathrm{e})$ werc found to be 9.8 (1) nm and $0.0010(\mathrm{t})$, respectively. The inot (b) shows the morphological yiew of the NPa. The average particle size way calcnlated by rounting over 150 NPs and found to be $10.9 \mathrm{~mm}$ with the standard deviation $\sigma=2.8 \mathrm{~nm}$.

3.2. Magnetil meavurcment 1 he magnetisation foop of such keg $\mathrm{O}_{4}$ tertolluid was rouoried at foom temiperavure, as shown in Etg 3 . Lie loop khows is 
4. Sharkar, M Chand, S, Kumar, K.N. Singh, G.A. Basheed, S. Thakar, R. P. Pant

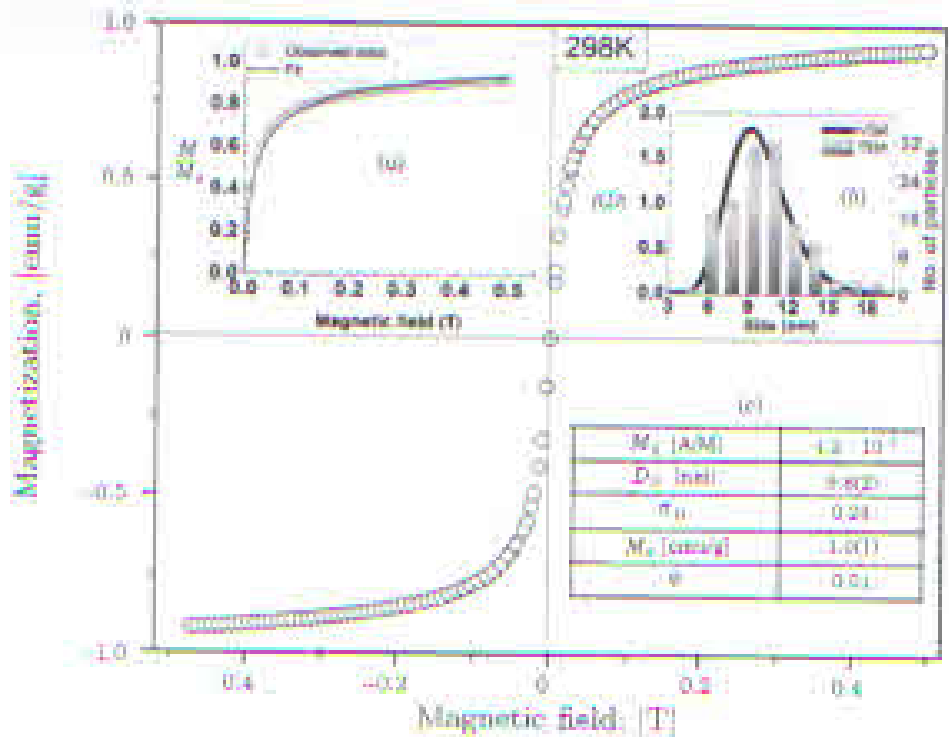

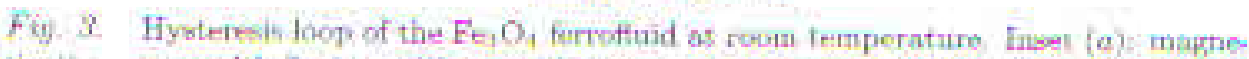
tization curse with fis: insel (6): particle size distribution from VSM und ThM resullo-

negliguble hysteresis with $2.5 \mathrm{Oe}$ as the noescive field $\left(H_{\xi}\right)$ value, which evidenions that the particles ure of superparamagnetic natne. The magnetic statn of such a system can be described by $|5,6|$

$$
M=\int_{0}^{\infty} L(D) f(D) i D .
$$

where.

$$
\begin{aligned}
& L(\omega)=M_{n}\left(\operatorname{cth} \alpha-\frac{1}{n}\right), \quad a-\frac{\mu H}{k I}, \quad M_{E}=M_{a r} ; \\
& f(D)=\frac{1}{\sqrt{2 \pi} \sigma_{n} D} \exp \left\{\frac{-\ln \left(D / D_{0}\right)^{2}}{2 \sigma_{D}^{2}}\right\}, \quad \int f(D) d D=1
\end{aligned}
$$

Hore $L(\alpha)$ is the Iujtevin function, $f(D)$ is the lopnormit size distribution, in is the magnetic moment, $7 \mathrm{D}$ is a standard deviation, $H$ is the applied magnetic field, $k$ is the Bolezmann constast, $T$ is the temperature, $M$ ! is the lluid nagrvetization, Q is the molume fraction of FNPs in the ferrotuid (FF), $M_{d}$ is the domain maknetization, and $D_{0}$ is the median chaneter. Inset $(u)$ stiows the fiest fit to the $M-\mu$ curve yielding the purticle size distribution from. VSM It must be noted that the saturation maggetization $M_{\text {f }}^{t}$ is very low, i.e femu/g if compared to the bulk salues 84 emu/g.

3.3. FMR measurement. These messurements an the stmple wern nude using the $9.54 \mathrm{GLl}$ microwave frequency with a power of $1.03 \mathrm{~mW}$. The sample wis cooled down from $208 \mathrm{~K}$ in zero maynetic field to $4 \mathrm{~K}$ and the spectra were reeorded whilh raising the temperature. During the field covalod measurement, the sample was conled in a magnetic field $\left(H_{\text {upp }}\right)$ of : T and the spoct ra were recorded et $\mathrm{tK}$ with $0^{\circ}$ and $90^{\circ}$ in plane ungular orientations. By mpplying a linear model

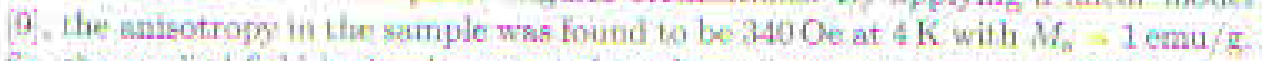
So. the applied field is simply expecied to align all moments in one direction thus 

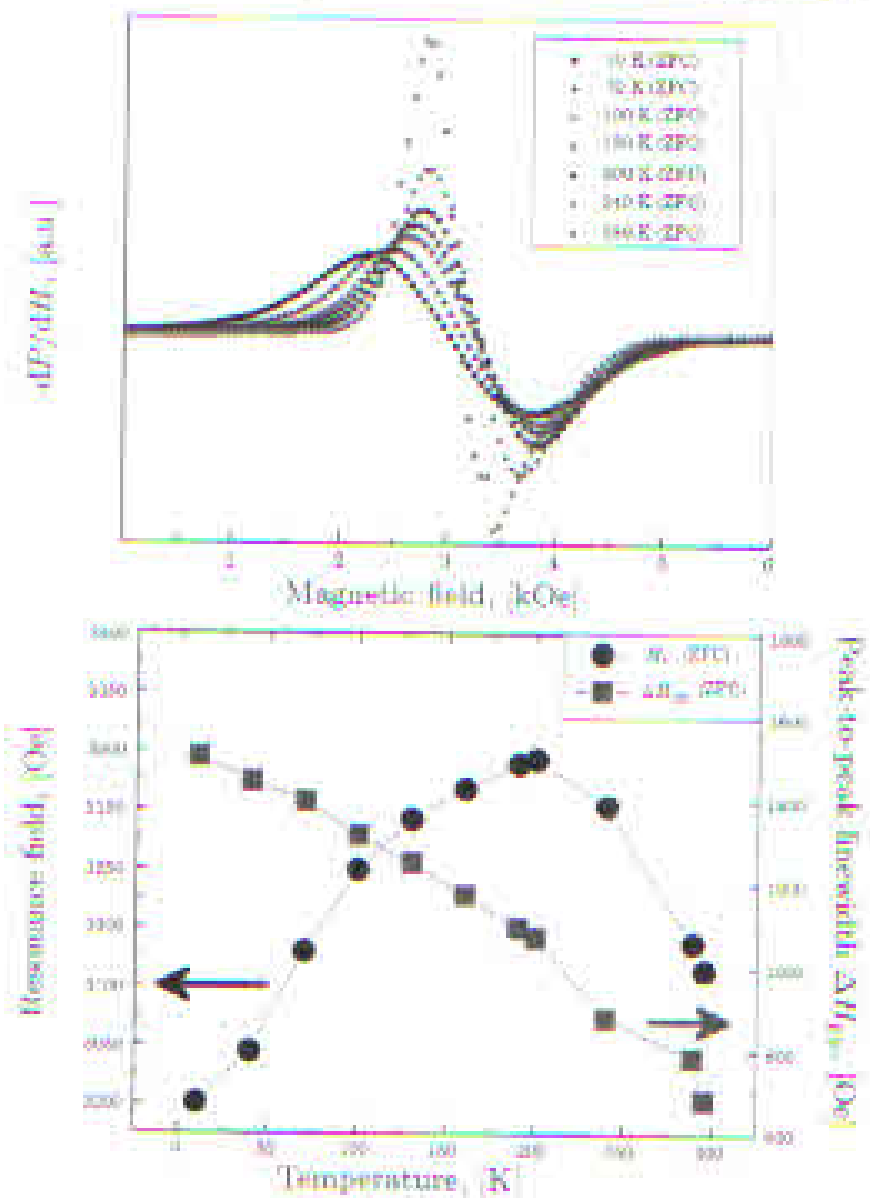

(b)

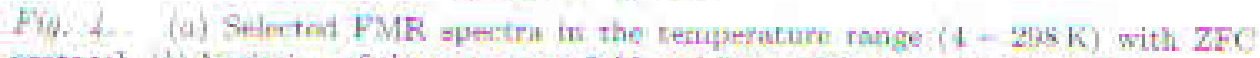
protocol (b) Vuriacion of the resanance field and line width with the temperature

minimizing the oricntational ifistribution fumethis 10 Fig. 4 stows the recordod low temperature FMR spectra.

in ZFC, the resonand field shops a non-monotonic behavior with a nuximum of $200 \mathrm{~K}$ On the other hand, $\Delta H_{\mathrm{i}, \mathrm{p}}$ shows a regalar fall characteristic of the PNP. with an incteas in tempersture (11) Snch temperature dependence of line width in a system composed of magnetic nasoparticles will he described elsewhore in itotall

To explain the Ixthavior of $H_{5}$, wo employed the most trequently used NeefBrown model With the Next-Brown model, lihe relaxation viate between double poritutial welle for an ictoal superparamugnetic system in the absence of any field

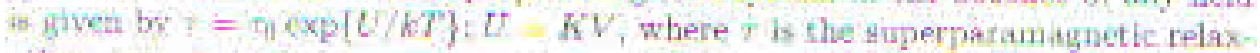
ation tano, to is the pro-exponential factor, $U$ is the maguecic anisotropy enerisy, $k$ is the Boltzmami constant, and $T$ is the temperature But is detormine the ungnetin yliase of the system (t.e. fernomagnetism/superparatuagnetism) and to

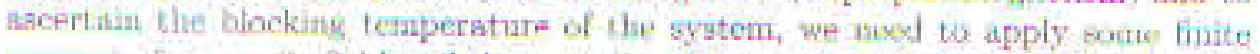
umour of magnetic field and then we directly mexaure the maysutic property of the system like magnetizution or ausceptitility. This situatiou results in the alignmost of nore tuagnetic momeus parallel ta. the applied field $(H)$ if compared to the antifiuratlet eanifigaration. to nther words, an ideal doubic potential dencrib- 
ing a superparamagnetic system is now perturbed to a diatorted double potentiol well system senaratid by the activation energy barriar, which will change from $E_{\mathrm{a}}=K V$ to $E_{\mathrm{n}}^{-}=K V\left(1-H_{/} / H_{\mathrm{a}}\right)^{2}$ and to $E_{2}^{4}=K V\left(1+H / H_{3}\right)^{2}$. for the antiparnllet and parallel configurations, respectively. It is now clearly visible that tha former with a lesser energy harrier will play an tuportant role if compared to the latter one in determining the unblocked state. The extent of perturbation depends in the stressth of the upplied field $\mathrm{H}$. In DC-magnesination and $\mathrm{AC}$-surceptibilits menswroments, the system is placed in o uagnetic fiele with the condition $H<I I$,

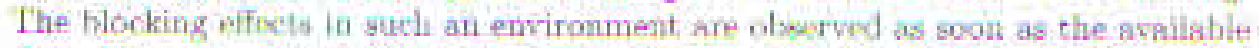
thermal eiergy becomes enough to flip the untiparallel moments to makn than parallet along, the fietd The blocking temperature is oliservod whou the superparanugnetic relaxation time matches with $T_{m \text {.t. }}$ Under these circumstancer, the model unfer dircusetun gets modified mathematically and can be expressed as follows $[12]$ :

$$
T^{-}=r_{0} \exp \left\{\frac{U}{K T}\right\}: \quad U=K V\left(1+\frac{H}{H_{\mathrm{a}}}\right)^{2}
$$

In addition to this, if is expectud that Larmor relaxation processes in these elassical apin syotem is affocted by the superparamsgnet ut reluxation muchunism of MNPy. In this way, the resconance fitd $f\left(H_{r}\right)$ can be regarded as a manifestatiun of two mompetituve dyuame changes taking place in the systum. Using requigite vaiuos $\left(M,=1 \mathrm{cmin} / \mathrm{F}_{\mathrm{s}}\right.$, volune corresposting to $D=9.8 \mathrm{~nm}, H_{\mathrm{a}}=340 \mathrm{Oe}, \mathrm{H}=\mathrm{H}_{\mathrm{n}}$ $\left.\hat{K}=85 \mathrm{Jm}^{-3}, k \quad 1.38 \cdot 10^{-23} \mathrm{J \textrm {K } ^ { - 1 }}\right)$ in $\mathrm{Eq},(2$, we cilculated $U / k T$ for the paralled/antiparallel potential well of $\mathrm{Flg}$, 5 mormspouding to the $\mathrm{ZFC}$ resonance feld values of FMR, and its variation with the temperature is shown in Fig eda $A$ close look of Fig. $6 b$ shows that $1 / 7 / k T=1$ is found exictly neat to a temperature region $(\sim 222 \mathrm{~K}$ ), where the sybtem loses nearly all Its anisotropy in the amgalus

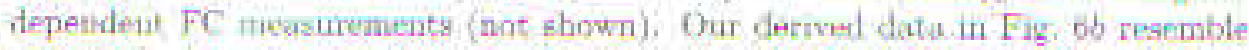
the Mossbener reanits discissod by Rondinone et al 2 . But similianesusly, the bfise curve reprosectang the relaxation from the potential weil with parallel configuration is still not able to crass $U / K T=1$, which is due to hindrance by a tery tugh energy barrier crmatenl from the large magnitude of the applied field over the suisotropy field $\left(F \quad H_{+} ; I_{3}\right.$ ) As a result, dup to the eulisured energy berrier resulting for $\mathrm{FNH} s$ in an aligned potenfial well makes the dynamic rejaxation procese infeasible from this well even ubove $I_{\mathrm{b}}$. From Fig, $6 \hat{6}$, we conclude that the oheerved temperature region $\sim 225 \mathrm{~K}$ shows the blocking effocts in the system.

4. Conclusion. A doubles surfoctant water-besed magnetit- ferrottudid was chemically nynthorizut and studied for its srructural and tnagnestic properties by

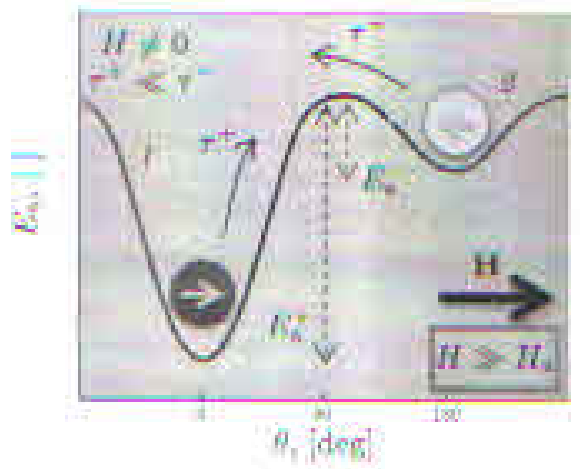

Fig. 5 A hughly distortat drobin potential well system in FMIR with $H_{t}=H>H_{n}$. 

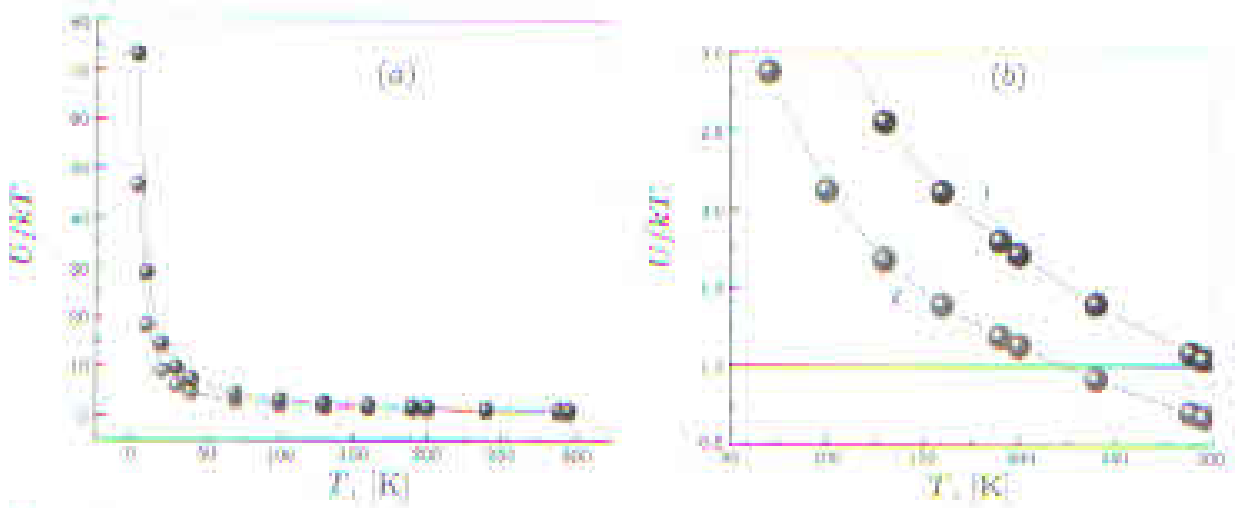

Fig: a. (a) Voriation of $U / K T$ is. I for ZFC datiset: $(b)$ a mapnitiod view of the region, where $0 ; k T$ becormen unity

XRD, ILM, VSM and FMR fechakguth. The tumgecte manopurticles were found bo be with a very low saturation magnetization $\left(M_{k}\right)$. This was explained with the explatuation of dead layer, donble surfartant coating. The low teraperature unulysis of FMR datia hi the ZFC protocol revealed interesting features. The resonaner field in ZFC ghows maxima at $\sim 200 \mathrm{~K}$. The application of a linear model asd a lifelBrown moded to the FMR shows the blocking effecth in the system at $\sim 225 \mathrm{~K}$.

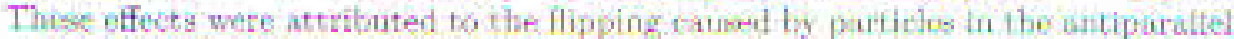
potential weil.

Acknowledgements. The work was supported by the Depariment of Saence \& Iechnology, Intia (project No. GAP 193532):

\section{REFERENCES}

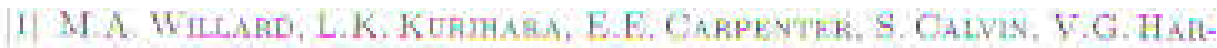

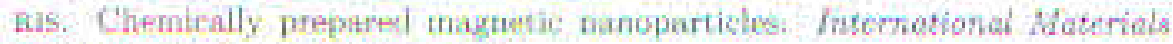
Revienes, vol. 49 (2164), pp $) 4$.

I] A.J.THONDENONE; C.ET, Z.A.ZHANG. Determination of magnetic anisctropy distribution and anisotropy cunstant of manganese splned ferrite inupgarticles J. Phos. Chem. B. vol. 105 (2001), pp. 7967-7971.

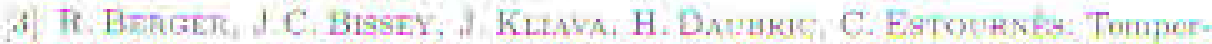
ature dependepce of superparastagnetic resosunce of tron cxide uanoparticles.

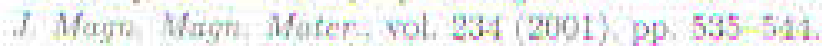

4. K. UGADEL. Temperature-dependent dynamical hehavior of maneparticlis as probed by fertomagnitic fosotuacy using Landau Lffehitz Cllbert dynamics it a classhat spin model. Phys. Rev. B, vel $73(2006), n p .212405$.

5 R.C. Woodowati, A. Hreses, T.G.ST Pierfet. A comparisnn of nethucts for the messorernent of the partichesige distribution of magnetic manopsticles. Atopt Crast. yol. 40 (2007), pp, $8495-8500$.

16 F.V. UPADHYAY, K. PAREKH, R V. MEHYA Spim glass transition in a model magnerie Huid: Flieturon spin resonance isvestigution of $\mathrm{Mn}_{0} \mathrm{Zn}_{0} \mathrm{Fe}_{2} \mathrm{O}_{4}$ nusoparticles dispersed in kerosene. Phys. Prt. B. vol. 6s (2003), Pp. 224434.7. 
A. Sharikar, M. Chand, 5. Kumar, V.N.Singh, G. A. Basbeed, S. Thaiker, R.P Pant

7) T. KIM. M. SHMA. Prolucer magnetisation in magnetic oxide nanoparticles.

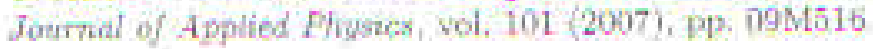

8. C.1.OCONoH, Y.S.L. Bussos, S. L. Ferrite syuthesin in microstructurel medic: Template effects und maguetic properties. I Appl. Pheps., vol 81 $(1997), \mathrm{pp} .4741$.

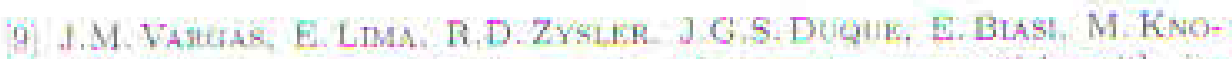
BEL. Effective anisotropy field variation of magnetite manoarticles with size roduction. Eis, Phys. J. B, val, 64 (2008), pp. $211-218$.

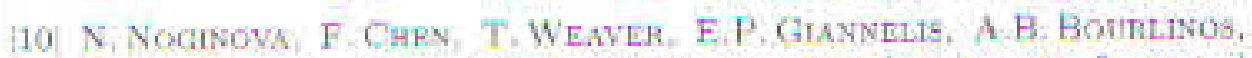
V.A. AThAHKiN Magnatic resonanre in munuperticles: between ferro and paramagnetisin Journat of Phosics: Conden Mat, vol. 19 (2007), pp. 246208.

11) K.H.HSE, J H. WU, Y.Y.HUANG, L.Y WANG, H.Y L.F, , G. Lis Critical size effects on the magrotic resonance in $\mathrm{Fes}_{4} \mathrm{O}_{4}$ nanopurticles 7 . Appl Phys, vol, $97(2005)$, pp 114322$)+143224$

12 R.K. ZneNG, H. GU, B.XV, X,X.ZHANG. The origis of the not-monotonic field dependence of the blocking temperatiure in magnetic nannparticles. $J$. thys, Corulto. Mat, wh $18(2000)$, Tp, 5905.

13] D. Senavizs, D. Bazdoman. Superperamagnetism and Monto Carto sumu-

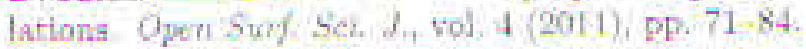

Ficcived 20.07.2013 